Full Paper

\title{
Influence of Nafion Coatings and Surfactant on the Stripping Voltammetry of Heavy Metals at Bismuth-Film Modified Carbon Film Electrodes
}

\author{
Carla Gouveia-Caridade, Rasa Pauliukaite, Christopher M. A. Brett* \\ Departamento de Quimica, Universidade de Coimbra, 3004-535 Coimbra, Portugal \\ *e-mail: brett@ci.uc.pt
}

Received: January 6, 2006

Accepted: February 22, 2006

\begin{abstract}
Nafion polymer coated bismuth-film-modified carbon film electrodes have been investigated for reducing the influence of contaminants such as surfactants in the anodic stripping voltammetry of trace metal ions. The influence of the coating on electrode response has been tested with both ex situ and in situ bismuth film deposition, with and without the polymer coating. The electrode assemblies and interfacial characteristics in the presence of the non-ionic surfactant Triton-X-100 have been probed with electrochemical impedance spectroscopy. The Nafion coating successfully decreases the adsorption of Triton on the bismuth film surface, and demonstrates that this strategy allows measurement of these trace metals in environmental samples containing surfactants.
\end{abstract}

Keywords: Nafion, Bismuth film electrodes, Carbon film electrodes, Triton-X-100 surfactant, Stripping voltammetry, Electrochemical impedance

DOI: $10.1002 /$ elan.200603482

\section{Introduction}

Bismuth is an environmentally friendly element with a very low toxicity [1], and is widely used in the pharmaceutical and cosmetic industries [2]. Since the year 2000, bismuth film electrodes have become an attractive new subject of electroanalytical investigations as a potential replacement for mercury and mercury film electrodes [3].

During the last 5 years different types of bismuth electrode have been applied to the determination of heavy metals using stripping voltammetry $[1,4]$. Bismuth films have been deposited on different carbon substrates, particularly on glassy carbon [3, 5-17], carbon fiber [3, 11], screen-printed carbon [18, 20], carbon paste [20-23], electrically-heated carbon paste [24], and boron-doped diamond electrodes [25], showing excellent advantages with respect to mercury films. Bismuth bulk electrodes were also studied and compared with the bismuth films [26]. Recently, the formation of bismuth films on novel carbon film resistor electrodes has been evaluated [27]. These films were deposited in different ways, using in situ or ex situ deposition at constant potential, as well as ex situ at constant current and by potential cycling. The bismuth film electrodes were then characterized using cyclic voltammetry and electrochemical impedance spectroscopy, and the data obtained confirmed that the best method for Bi deposition is at constant potential either in situ or ex situ; films formed in both these ways had very similar electrochemical properties. Thus, carbon films were found to be excellent substrates

Electroanalysis 18, 2006, No. 9, 854-861 for bismuth and showed an analytical sensitivity for a number of heavy metals, particularly for $\mathrm{Zn}, \mathrm{Cd}$, and $\mathrm{Pb}$, similar to or better than Bi films deposited on other carbon substrates [27].

Since natural environmental samples, in which traces of heavy metals need to be analyzed, usually contain some surface-active substances, it is important to investigate their influence on the analytical performance of bismuth film electrodes. Usually these substances adsorb at electrode surfaces and block them, disturbing deposition of the analyte [6]. The problem can usually be solved by applying a protective polymer film such as Nafion, as shown at carbon film [28] and mercury film [29] electrodes, or at Bi films deposited on glassy carbon electrodes [30].

In previous recent work, [31], the influence of surfactant on the determination of $\mathrm{Cd}$ and $\mathrm{Pb}$ at carbon film electrodes was studied by electrochemical impedance spectroscopy (EIS). Here, Bi films have been deposited either ex situ (for $\mathrm{Zn}$ determination) or in situ (for $\mathrm{Cd}$ and $\mathrm{Pb}$ determination) at constant applied potential. A protective layer of Nafion has also been applied to decrease the adsorption of surfaceactive substances. The films obtained were characterized by cyclic voltammetry and electrochemical impedance spectroscopy. The square-wave anodic stripping voltammetric response to zinc, cadmium, and lead ions at Nafion-coated bismuth film electrodes has been successfully demonstrated and evaluated.

(C) 2006 WILEY-VCH Verlag GmbH \& Co. KGaA, Weinheim 


\section{Experimental}

\subsection{Chemicals and Solutions}

Bismuth(III) nitrate, lead(II) nitrate, cadmium(II) chloride, and zinc(II) chloride were obtained from Sigma (Germany). Nafion, 5\% solution in alcohol, was purchased from Aldrich (Germany), and Triton X-100 (Sigma, Germany) was used as received after appropriate dilution. Sodium acetate and acetic acid (Riedel-de Haën, Germany) and Millipore Milli-Q nanopure water were used to prepare $0.1 \mathrm{M}$ acetate buffer, $\mathrm{pH}$ 4.45. Stock solutions of the salts mentioned above, concentration $1 \mathrm{~g} \mathrm{~L}^{-1}$, were prepared in acetate buffer and stored at room temperature. They were diluted as required before measurements.

\subsection{Instrumentation and Methods}

A three-electrode cell, containing the carbon film working electrode, a platinum foil counter electrode and a saturated calomel electrode (SCE) as reference, was used for voltammetric measurements. Preparation of the cylindrical carbon film electrodes, area ca. $0.20 \mathrm{~cm}^{2}$, from carbon film electrical resistors is described elsewhere [32, 33]. They were pretreated in acetate buffer by potential cycling from -1.5 to $+1.5 \mathrm{~V}$ vs. SCE 10 times before first use.

Square-wave and cyclic voltammetry measurements were performed using a computer-controlled $\mu$-Autolab Type II potentiostat/galvanostat with GPES 4.9 software (Eco Chemie, Netherlands). For square-wave anodic stripping voltammetry (SWASV) the frequency was $25 \mathrm{~Hz}$, step potential $4 \mathrm{mV}$, and amplitude $25 \mathrm{mV}$; the potential was swept from -1.4 to $+0.4 \mathrm{~V}$ vs. SCE or from $-0.9 \mathrm{~V}$ to $0.0 \mathrm{~V}$, after an equilibration time of $15 \mathrm{~s}$.

Electrochemical impedance measurements were carried out in the same electrochemical cell with a PC-controlled Solartron 1250 Frequency Response Analyzer coupled to a Solartron 1286 Electrochemical Interface using ZPlot 2.4 software (Solartron Analytical, UK). A sinusoidal voltage perturbation of amplitude $10 \mathrm{mV}$ was applied, scanning from $65 \mathrm{kHz}$ to $0.1 \mathrm{~Hz}$ with 10 points per frequency decade, auto-integration time $60 \mathrm{~s}$. Fitting to electrical equivalent circuits was performed with ZView 2.4 software.

All experiments were carried out at room temperature $\left(25 \pm 1^{\circ} \mathrm{C}\right)$.

\subsection{Formation of Bismuth Films}

Bismuth films were formed by deposition on the carbon film substrate at constant applied potential. The deposition was performed in two ways: ex situ in a separate solution prior to characterization experiments or measurement of trace metals, or in situ in the same solution. The composition of the deposition solution was $0.1 \mathrm{M}$ acetate buffer solution containing either $1 \mathrm{mg} \mathrm{L}^{-1} \mathrm{Bi}(\mathrm{III})$ (ex situ deposition) or $400 \mu \mathrm{g} \mathrm{L}^{-1}$ (in situ deposition). The electrode was condi- tioned before deposition at $+0.3 \mathrm{~V}$ for $300 \mathrm{~s}$ to re-oxidize any heavy metal species present at the electrode surface. Bismuth was deposited at $-1.4 \mathrm{~V}$ for $300 \mathrm{~s}$ or $-1.2 \mathrm{~V}$ vs. SCE for $120 \mathrm{~s}$ for ex situ or in situ deposition, respectively, and the solution was stirred both during conditioning and during deposition.

The metals to be analyzed by SWASV were deposited at $-1.4 \mathrm{~V}(\mathrm{Zn})$, and $-1.2 \mathrm{~V}(\mathrm{Cd}, \mathrm{Pb})$ vs. SCE for $120 \mathrm{~s}$ and the electrode equilibrated after deposition for $15 \mathrm{~s}$ before the square-wave stripping scan.

\subsection{Nafion Coated Bismuth Film Electrodes}

The Nafion coating was made by applying $5 \mu \mathrm{L}$ of a solution of $0.25 \mathrm{wt} \%$ Nafion in alcohols, followed by $3 \mu \mathrm{L}$ of $N, N^{\prime}-$ dimethylformamide, directly on top of the pretreated surface of the carbon film electrode, with a motorized electronic micropipette (EDP-Plus, Rainin, USA). After evaporation of the solvents, the film was cured with a jet of warm air for about $1 \mathrm{~min}$. This procedure leads to a film of ca. $1 \mu \mathrm{m}$ thickness. The bismuth film was then deposited on the Nafion-coated carbon film electrode, the bismuth layer being formed between the carbon film substrate and the Nafion coating.

\section{Results and Discussion}

The determination of $\mathrm{Zn}, \mathrm{Cd}$ and $\mathrm{Pb}$ by SWASV at the bismuth film modified carbon film electrodes was used to demonstrate the influence of surfactant on the ASV response of these electrodes without and with a protective Nafion coating. Electrode assemblies with $\mathrm{Cd}$ and $\mathrm{Pb}$ on Nafion coated bismuth in situ modified carbon film electrodes were characterised by EIS.

\subsection{Influence of Triton on $\mathrm{Zn}$ Determination}

In previous work [27] it was found that the best response of bismuth modified carbon film electrodes to zinc ions in solution was obtained by depositing the bismuth film ex situ; this avoided the in situ decrease in deposition efficiency due to a small amount of hydrogen evolution at the rather negative deposition potential of $-1.4 \mathrm{~V}$ vs. SCE. Following ex situ deposition of bismuth, the SWASV of zinc was carried out. Typical stripping responses of the modified electrode to $400 \mu \mathrm{g} \mathrm{L}^{-1}$ of $\mathrm{Zn}$ in the absence and in the presence of increasing amounts of Triton-X-100 are shown in Figure 1.

The bismuth-modified electrode shows a well-defined zinc stripping peak in the absence of the surfactant, and a peak potential of $-1.00 \mathrm{~V}$ vs. SCE. The presence of Triton has a large influence on the peak current even at low concentrations: in the presence of $1 \mathrm{mg} \mathrm{L}^{-1}$ of Triton the signal decreases more than $50 \%$ and is completely suppressed at concentrations higher than $8 \mathrm{mg} \mathrm{L}^{-1}$. There was 


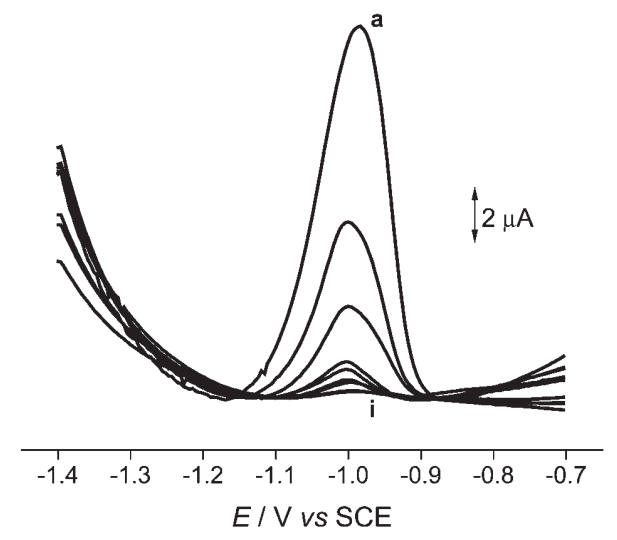

Fig. 1. Square-wave stripping voltammograms at ex situ bismuth film modified carbon film electrodes for $400 \mu \mathrm{g} \mathrm{L}^{-1}$ zinc in $0.1 \mathrm{M}$ acetate buffer ( $\mathrm{pH} 4.45)$ in the presence of increasing concentrations of Triton-X-100: a) 0, b) 1, c) 2, d) 3, e) 4, f) 5, g) 8, h) 10 , and i) $20 \mathrm{ppm}$. Experimental conditions: $t_{\mathrm{dep}}=120 \mathrm{~s}$ at $-1.4 \mathrm{~V}$ vs. SCE, square-wave frequency $25 \mathrm{~Hz}$, potential increment $2 \mathrm{mV}$, amplitude $25 \mathrm{mV}$, equilibration time $15 \mathrm{~s}$.

no evidence of any shift in the peak potentials. The same behavior was obtained at in situ deposited bismuth film modified glassy carbon electrodes by Kefala et al. [30].

\subsection{Influence of Triton on the Determination of $\mathrm{Cd}$ and Pb}

In [27] it was shown that Bi films deposited in situ on carbon film electrodes had an excellent analytical response to $\mathrm{Cd}$ and $\mathrm{Pb}$ ions, and showed better reproducibility than those prepared ex situ. Considering this, the determination of $\mathrm{Cd}$ and $\mathrm{Pb}$ ions was performed at electrodes modified with bismuth produced in situ. Representative voltammograms

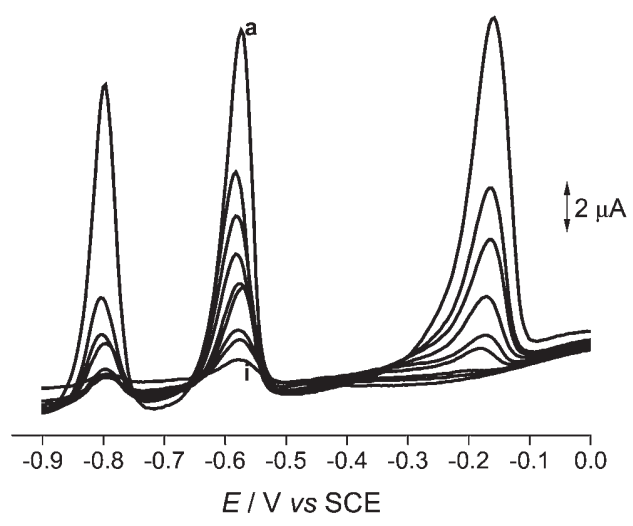

Fig. 2. Square-wave stripping voltammograms at in situ bismuth film modified carbon film electrodes for $100 \mu \mathrm{g} \mathrm{L}^{-1}$ cadmium and lead in $0.1 \mathrm{M}$ acetate buffer $(\mathrm{pH} 4.45)$ in the presence of increasing concentrations of Triton-X-100: a) 0, b) 1, c) 2, d) 3, e) 4 , f) 5 , g) 8 , h) 10 , and i) $20 \mathrm{ppm}$. Experimental conditions: $t_{\text {dep }}=120 \mathrm{~s}$ at $-1.2 \mathrm{~V}$ vs. SCE, square-wave frequency $25 \mathrm{~Hz}$, potential increment $2 \mathrm{mV}$, amplitude $25 \mathrm{mV}$, equilibration time $15 \mathrm{~s}$. for SWASV in solutions containing $100 \mu \mathrm{g} \mathrm{L} \mathrm{L}^{-1} \mathrm{Cd}$ (II) and $\mathrm{Pb}(\mathrm{II})$ in the presence of increasing concentrations of Triton-X-100 are illustrated in Figure 2.

In the absence of surfactant, the electrode displays welldefined cadmium and lead peaks, with peak potentials of $-0.80 \mathrm{~V}$ and $-0.58 \mathrm{~V}$. Figure 2 also shows the bismuth peak at $-0.17 \mathrm{~V}$. The addition of Triton causes a severe reduction in peak current, owing to partial blocking of the electrode surface. Cadmium ion is more sensitive to this than lead ion in the acetate buffer solution employed. In the presence of $1 \mathrm{mg} \mathrm{L}^{-1}$ of Triton the suppression of the cadmium signal was about $70 \%$.

It should also be noted that, after addition of Triton, the bismuth peak is shifted to more negative potentials by 30 $40 \mathrm{mV}$ and the peak current decreases with increasing amounts of the surfactant, and was completely suppressed with addition of $8 \mathrm{mg} \mathrm{L}^{-1}$.

\subsection{Nafion Coated Bi Film Electrodes}

The effect of surfactant molecules in decreasing the response of an electrochemical sensor can be diminished by using a protective film [28-30]. Often these films are made from polymers, and the one most used for trace metal ion analysis is the cation exchange polymer Nafion. The Nafion coating is easy to prepare, and the antifouling effect is significant [34].

\subsubsection{Potential Window}

Bismuth film electrodes without and with the Nafion polymer coating were first characterized by cyclic voltammetry in order to examine their potential window and the magnitude of the background currents, but only in the negative potential range due to oxidation of $\mathrm{Bi}$ itself at $-0.2 \mathrm{~V}[3]$.

The current - potential profile for uncoated and Nafioncoated ex situ bismuth film modified carbon film electrodes is shown in Figure 3. Bismuth film electrodes without Nafion-coating gave similar results to those in [27], bismuth films deposited in situ and ex situ showing the same behavior. The Nafion coated Bi film gives almost identical voltammograms for the two $\mathrm{Bi}$ deposition methods, however, a more negative potential limit was obtained and smaller background currents. This change can be attributed to the chemical characteristics of Nafion, which can contribute to a more efficient electrodeposition of the $\mathrm{Bi}$ film and also confer physical stability to the Bi film formed.

\subsubsection{SWASV of Heavy Metals in the Presence of Surfac- tant}

Figure 4 shows typical voltammograms obtained for $\mathrm{A}$ ) $400 \mu \mathrm{g} \mathrm{L}^{-1}$ zinc and B) $100 \mu \mathrm{g} \mathrm{L}^{-1}$ cadmium plus $100 \mu \mathrm{g} \mathrm{L}^{-1}$ lead at a Nafion-coated bismuth electrode. Once again, the bismuth deposition was carried out by the ex situ procedure for $\mathrm{Zn}$ and in situ for $\mathrm{Cd}$ and $\mathrm{Pb}$ analysis. Comparing these 


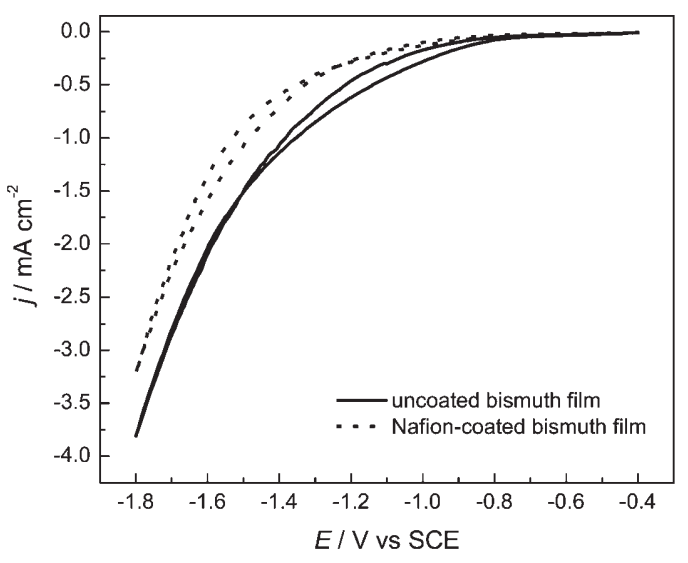

Fig. 3. Cyclic voltammograms at bismuth film modified carbon film electrodes with and without Nafion coating, sweep rate $50 \mathrm{mV} \mathrm{s}^{-1}$. Bi film formed ex situ at constant potential in $0.1 \mathrm{M}$ acetate buffer $\mathrm{pH} 4.45$.

responses with those of the bismuth electrodes without the polymer film, in Figures 1 and 2, it can be seen that even in the absence of Triton, the peak currents are lower with the Nafion-covered electrodes, by $75 \%$ for $\mathrm{Zn}$ but by only $4 \%$ for $\mathrm{Cd}$ and $\mathrm{Pb}$, the decrease in signal being due to diffusion limitations imposed by Nafion. This contrasts with a decrease of $15 \%$ at the mercury thin film electrode [34]. The $\mathrm{Zn}$ signal decreased so much probably due to a small amount of hydrogen evolution during deposition at the Nafion-coated Bi film as was also observed with in situ deposited Bi films at these potentials. The sensitivities are 2.7, 57.8, and $116 \mathrm{~A} \mathrm{~cm}^{-2} \mathrm{M}^{-1}$ for $\mathrm{Zn}, \mathrm{Cd}$ and $\mathrm{Pb}$ at Nafioncoated Bi film electrodes, respectively, with relative errors between different electrodes of 13.6, 1.9 and 2.1\% $(n=3)$; repeatability is better than $2 \%$ in all cases. The lower sensitivity and reproducibility for zinc can be attributed principally to the small amount of hydrogen evolution that occurs at the deposition potential.

After addition of $1 \mathrm{mg} \mathrm{L^{-1 }}$ of Triton, the $\mathrm{Zn}$ signal obtained with the Nafion-coated electrode decreases but more slowly than with the bismuth film electrode without Nafion coating, see Figure 5. Moreover, after consecutive additions of the surfactant ( 2 to $20 \mathrm{mg} \mathrm{L}^{-1}$ ) the response depends only slightly on Triton concentrations between 2 to $10 \mathrm{mg} \mathrm{L}^{-1}$, leading to the conclusion that this electrode is useful for the determination of $\mathrm{Zn}$ even in the presence of such relatively high concentrations of Triton.

A similar behavior to that of $\mathrm{Zn}$ was obtained for $\mathrm{Cd}$ and $\mathrm{Pb}$, following addition of $1 \mathrm{mg} \mathrm{\textrm {L } ^ { - 1 }}$ Triton. However, increasing the Triton concentration seems to lead to a more rapid decrease in peak current, the Nafion coating being apparently less effective. Although the concentration of $\mathrm{Zn}$ used is much higher $\left(400 \mu \mathrm{g} \mathrm{L}^{-1}\right)$ than that used for $\mathrm{Cd}$ and $\mathrm{Pb}\left(100 \mu \mathrm{g} \mathrm{L}^{-1}\right)$, the sensitivity of the $\mathrm{Bi}$ film for $\mathrm{Zn}$ is also lower. Moreover, $\mathrm{Zn}$ was determined only at ex situ Bi films [27], while $\mathrm{Cd}$ and $\mathrm{Pb}$ were analyzed at in situ deposited films (at ex situ deposited Bi films the response to $\mathrm{Cd}$ and $\mathrm{Pb}$ is small, see [27]). The influence of surfactant is
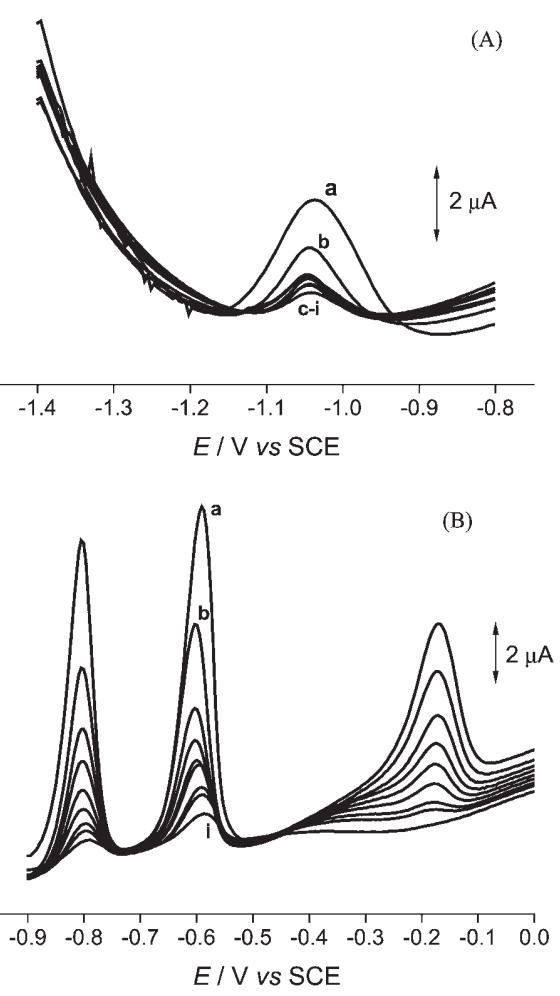

Fig. 4. Square-wave stripping voltammograms for A) $400 \mu \mathrm{g} \mathrm{L}^{-1}$ zinc and B) $100 \mu \mathrm{g} \mathrm{L}^{-1}$ cadmium and lead at Nafion-coated bismuth film electrodes in the presence of increasing concentrations of Triton X-100. Other conditions as in Figures 1 and 2.

easier to visualize from the square-wave stripping voltammetric response for $\mathrm{Zn}, \mathrm{Cd}$, and $\mathrm{Pb}$ as shown in Figure 5, normalized to that without Triton addition.

Although the molar concentration of $\mathrm{Cd}(\mathrm{II})$ is almost twice that of $\mathrm{Pb}(\mathrm{II})$, the signal intensity was higher for lead (Figure 4). To understand this, it should be remembered that in the solution $\mathrm{Pb}(\mathrm{II})$ is present as acetate complexes, and cadmium remains as $\mathrm{Cd}^{2+}$ (aq.). Thus, with a cation exchange polymer barrier, it would be expected that cadmium would give a higher response than the acetate-bound lead, since the latter would pass through the Nafion membrane to a lesser extent. However, it was shown in [35] that lead ions are involved in a ligand-exchange reaction at the polymersolution interface and become bound to the polymer. Cadmium ions, having a weaker tendency to complex with acetate and with a lower affinity for oxygen ligands, are therefore not incorporated into the polymer to the same extent as lead ions. The results of these interactions are manifested in the higher ASV peak currents for lead than for cadmium, equivalent to an additional preconcentration effect.

In Figure 4B the Bi stripping peak is also shown. This ion seems to be more sensitive to the presence of Triton, since the surfactant is adsorbed on the surface of the carbon film electrode and could make in situ bismuth deposition less easy. However, the SWASV results demonstrate that sufficient bismuth metal is deposited below the Nafion 

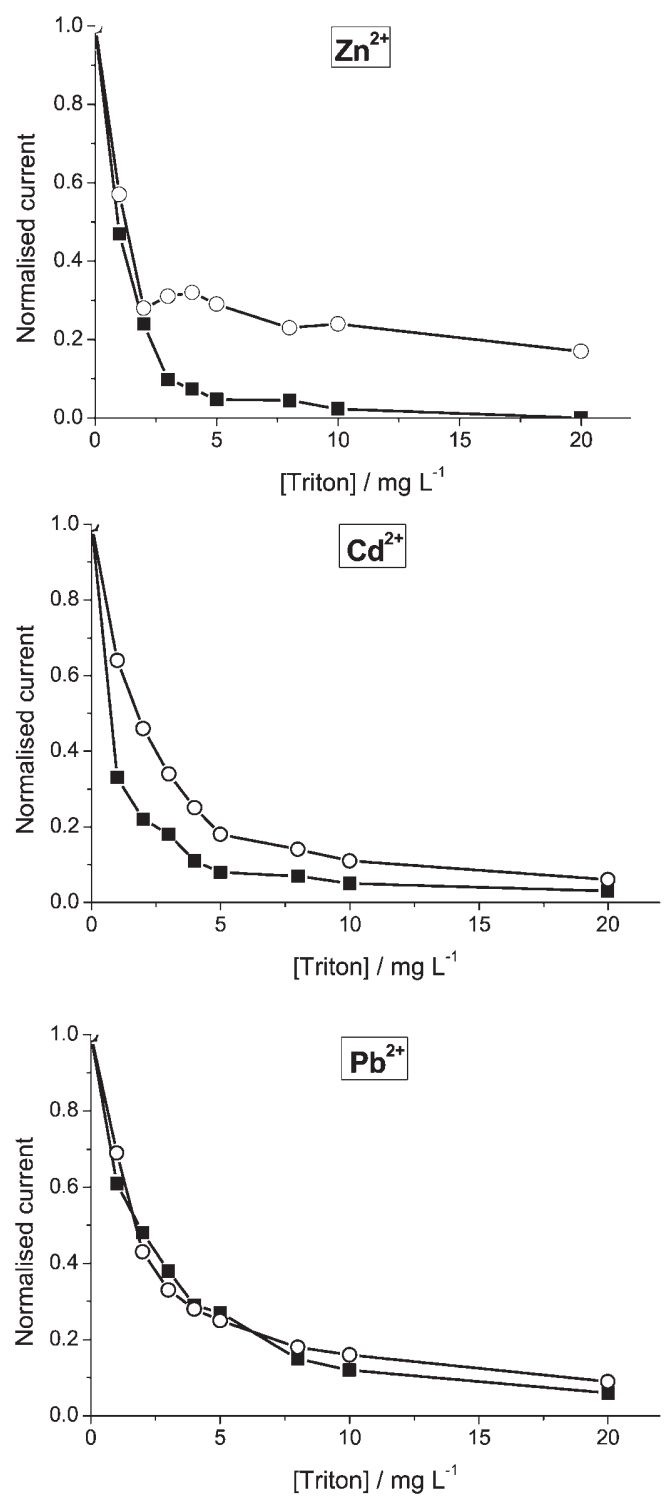

Fig. 5. Normalized square-wave stripping response for $400 \mu \mathrm{g}$ $\mathrm{L}^{-1}$ zinc, $100 \mu \mathrm{g} \mathrm{L}^{-1}$ cadmium and lead in the presence of increasing amounts of Triton X-100 at ( $\mathbf{\square})$ bismuth film modified electrode and (O) Nafion-coated bismuth film electrode. Other conditions as in Figures 1 and 2.

coating and the same nanomolar detection limits as in [27] are possible.

\subsubsection{EIS of Nafion-Coated Bi Films}

In order to throw light on the influence of the Nafion coating and of Triton-X-100 on the SWASV of cadmium and lead ions on Bi film electrodes, the characteristics of the electrodes before and after modification in solutions without and with Triton were investigated by electrochemical impedance spectroscopy. Solutions were not deoxygenated in order to be closer to the actual situation in the electroanalytical experiments; the effect of deoxygenation at carbon film electrodes has been discussed previously [28]. Similar experiments with zinc ions were carried out, but were influenced by hydrogen evolution at the $\mathrm{Zn}$ deposition potential of $-1.4 \mathrm{~V}$, such that meaningful deductions were difficult to make and are therefore not discussed.

The applied potentials for recording impedance spectra were chosen considering the deposition potential of the bismuth film in situ $(-1.2 \mathrm{~V}$ vs. SCE) and the stripping potentials of the metals concerned: $-0.8 \mathrm{~V}(\mathrm{Cd}),-0.6 \mathrm{~V}$ $(\mathrm{Pb})$ and $-0.2 \mathrm{~V}(\mathrm{Bi})$.

The sequence followed for the impedance experiments was as follows:

1) Spectra were recorded in $\mathrm{pH} 4.45$ acetate buffer solution for the Nafion-modified carbon film electrode;

2) Bismuth film deposition was carried out and spectra were recorded for the Nafion-coated bismuth-film modified carbon film electrode;

3) Cadmium and lead were then deposited from solutions containing similar concentrations as those used in SWASV, $100 \mu \mathrm{g} \mathrm{L}^{-1}$ of each ion, and spectra were recorded;

4) Triton was added to the solution, the metal deposition step was repeated and impedance spectra were again registered.

Spectra obtained are shown in Figure 6 in the complex plane and also as plots of the imaginary part of the impedance, $-Z^{\prime}$, vs. logarithm of frequency, $f$. These plots aid in visualizing the differences in the adsorption behavior and charge separation of the interfacial region in different experimental situations, as previously shown [31]: semicircles in the complex plane plots, which are due to a resistance, $R$, and a capacitance, $C$, in parallel, lead to peaks in the $-Z^{\prime \prime}$ vs. $\lg f$ plots, and the maximum, when $\omega R C=1$ ( $\omega$ in radians), corresponds to the time constant of the process.

Fitting of spectra was done using an equivalent electrical circuit, which comprised the cell resistance, $R_{7}$, in series with a parallel $R C P E$ combination. The constant phase element, $\mathrm{CPE}$, was necessary due to the nonhomogeneous surface and is modeled as a non-ideal capacitor of capacitance $C$ and roughness factor $\alpha$, where an $\alpha$ value of 1 represents a perfectly smooth surface. In some cases it was necessary to use a circuit with two parallel $R C P E$ elements in series to fit the data over the whole frequency range studied. Table 1 shows the data from the "high frequency" fitting, above 1 $\mathrm{Hz}$, where the spectra and the electrical circuit reveal the processes that occur at the electrode-solution interface, and only one $R \mathrm{CPE}$ is needed.

The cell resistance, $R_{7}$, at Nafion-coated carbon and bismuth films was ca. $7.0 \Omega \mathrm{cm}^{2}$. The roughness factor is almost the same under all conditions studied and it is a little bit higher than 0.90 , more than at the bare carbon film which has a value of ca. 0.85 [28]. The charge transfer resistance, $R_{1}$, tends to increase with less negative applied potentials, since at more negative potentials secondary processes can occur such as oxide reduction and metal deposition / reoxidation. 

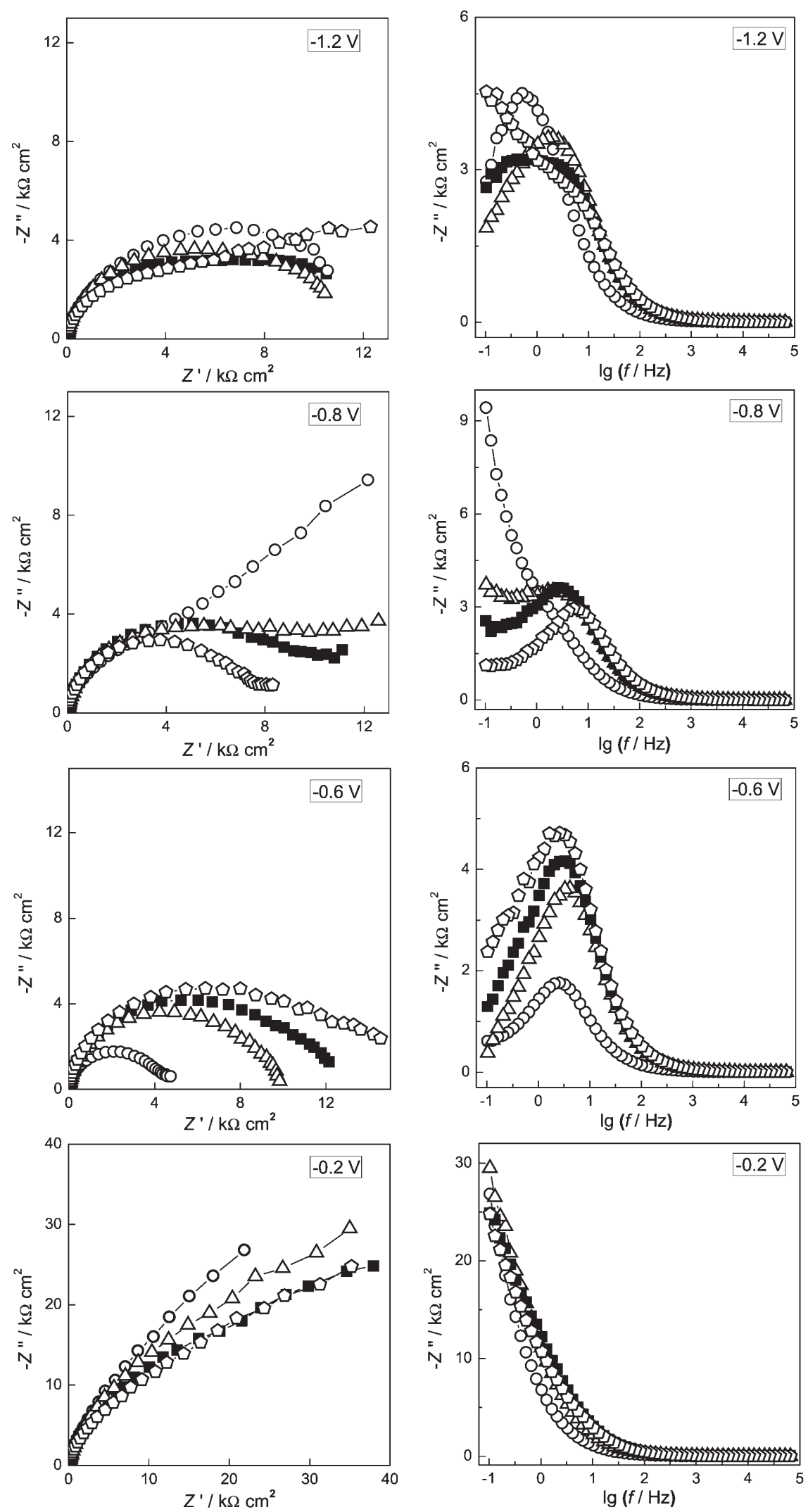

Fig. 6. Electrochemical impedance spectra as complex plane and $-Z^{\prime \prime}$ vs. $\lg (f / \mathrm{Hz})$ plots at different applied potentials in $0.1 \mathrm{M}$ acetate buffer $(\mathrm{pH} 4.45)$ at Nafion coated $(\circ)$ carbon film electrode and $(\triangle)$ bismuth modified carbon film electrode and, at the latter $(\mathbf{\square})$ with $100 \mu \mathrm{g} \mathrm{L}^{-1} \mathrm{Cd}^{2+}$ and $\mathrm{Pb}^{2+}$ and $(\bullet)$ with $100 \mu \mathrm{g} \mathrm{L}^{-1} \mathrm{Cd}^{2+}$ and $\mathrm{Pb}^{2+}$ in the presence of $1 \mathrm{mg} \mathrm{L}^{-1}$ Triton. 
Table 1. Data obtained from analysis of the impedance spectra of Figure 6, obtained in $0.1 \mathrm{M}$ acetate buffer $\mathrm{pH} 4.45 . R_{1}$ : charge transfer resistance; $C_{1}$ : capacitance, $\alpha_{1}$ : roughness exponent (CF: carbon film, BiF: bismuth film).

\begin{tabular}{llccr}
\hline Electrode/solution & $E(\mathrm{~V} v s . \mathrm{SCE})$ & $R_{1}\left(\mathrm{k} \Omega \mathrm{cm}^{2}\right)$ & $C_{1}\left(\mu \mathrm{F} \mathrm{cm} \mathrm{s}^{-2}\right)$ & $\alpha_{1}$ \\
\hline Nafion-CF & -1.20 & 8.31 & 15.7 & 0.92 \\
& -0.80 & 6.68 & 17.5 & 0.91 \\
& -0.60 & 4.01 & 17.9 & 0.92 \\
Nafion-BiF-CF & -0.20 & 23.9 & 21.4 & 0.90 \\
& -1.20 & 8.26 & 7.16 & 0.91 \\
& -0.80 & 8.17 & 5.02 & 0.92 \\
& -0.60 & 8.36 & 10.1 & 0.93 \\
$\mathrm{~Pb}^{2+}$ and Cd & -0.20 & 26.5 & 7.47 & 0.91 \\
& -1.20 & 7.29 & 6.39 & 0.90 \\
& -0.80 & 8.41 & 5.25 & 0.91 \\
& -0.60 & 9.63 & 7.06 & 0.93 \\
$+1 \mathrm{mg} \mathrm{L}$ & -0.20 & 24.7 & 7.06 & 0.91 \\
& -1.20 & 6.72 & 4.88 & 0.90 \\
& -0.80 & 6.88 & 5.15 & 0.92 \\
& -0.60 & 10.9 & 7.58 & 0.92 \\
& -0.20 & 21.0 & & 0.90 \\
\hline
\end{tabular}

The spectra showed the following trends:

- At - $1.2 \mathrm{~V}$, the complex plane spectra for all types of films without Triton in solution are similar depressed semicircles; in the presence of Triton, some alterations occur at low frequency, probably due to Triton's blocking effect. The peak in the $-Z^{\prime \prime}$ vs. $\lg f$ plot is at $\lg f=-0.4$ for the carbon film, and with the addition of bismuth shifts to higher values, changing again with addition of cadmium and lead ions, and no peak occurs in the presence of Triton. These plots are therefore particularly valuable in showing the changes occurring in the different situations.

- The complex plane spectra at $-0.8 \mathrm{~V}$ show greater differences between the different experimental conditions, particularly in the presence of Triton. Some effect of cadmium stripping is seen at low frequencies and the addition of Triton decreases impedance values, probably due to its adsorption and partial blocking of $\mathrm{Cd}$ reoxidation. Again, the peak in the $-Z^{\prime \prime}$ vs. $\lg f$ plot disappears on the addition of Triton.

- Surface oxide reduction occurs at $-0.6 \mathrm{~V}$ at the Nafioncoated carbon film electrode, leading to smaller impedance values and the complex plane impedance spectrum has a more perfect semicircular shape, as seen before [28]. The impedance increases after $\mathrm{Bi}$ deposition through the Nafion. Addition of the metal ions causes a small change, and addition of Triton causes a further slight increase in the impedance values. Almost no significant time constant shift was obtained in the $-Z^{\prime \prime}$ vs. $\lg f$ plots.

- At $-0.2 \mathrm{~V}$ the highest impedance values were obtained compared to the other potentials. At this potential bismuth re-oxidation has occurred, so the spectra are those of a Nafion-coated carbon film electrode, but with altered Nafion morphology. This was previously shown to be an irreversible factor after anodic stripping voltammetry at mercury thin film electrodes [28].
The observed differences at $-0.8 \mathrm{~V}$ and $-0.6 \mathrm{~V}$ at the Nafion-coated Bi film electrode can be related to the ability of only lead to be complexed by acetate anions from the buffer (see above, Sec. 3.3.2). The spectra clearly show that Triton alters the interfacial characteristics at all potentials studied, but the SWASV experiments do show that it does not occur sufficiently to block passage of the metal ions.

A further important point is that the charge transfer resistance at Nafion-coated Bi film electrodes with addition of $\mathrm{Cd}(\mathrm{II})$ and $\mathrm{Pb}(\mathrm{II})$ is significantly lower than at the Nafioncoated carbon film $\left(38.1 \mathrm{k} \Omega \mathrm{cm}^{2}\right.$ [28]), showing that Bi films facilitate heavy metal deposition. This suggests that it should be a better electrode for the electroanalysis of cadmium and lead than the Nafion-coated carbon film electrode.

\section{Conclusions}

Nafion-coated bismuth film electrodes, formed on carbon film resistor electrodes, have been characterized voltammetrically and by electrochemical impedance spectroscopy. Bismuth films were deposited at constant applied potential ex situ (for $\mathrm{Zn}$ determination) or in situ (for $\mathrm{Cd}$ and $\mathrm{Pb}$ analysis). The influence of a surfactant, Triton X-100, on heavy metal determination by SWASV was investigated at Bi film and Nafion-coated Bi film electrodes. The results obtained showed the advantages of the Nafion coating, which diminished the ability of Triton to block the bismuth film surface, although electrochemical impedance shows that it does modify the interface. It is still possible to determine traces of heavy metals even at rather high Triton concentrations, which is difficult without the Nafion coating.

Thus, Nafion-coated bismuth film electrodes on carbon film resistor electrode substrates can be successfully applied as heavy metal sensors for disposable or short-term use in natural samples in the presence of surfactant. 


\section{Acknowledgements}

Financial support from Fundação para a Ciência e a Tecnologia (FCT), ICEMS (Research Unit 103), Portugal, is gratefully acknowledged. C. Gouveia-Caridade and R. Pauliukaite thank for a PhD grant (SFRH/BD/18659/2004) and for a postdoctoral fellowship (SFRH/BPD/14518/2003), respectively.

\section{References}

[1] J. Wang, Electroanalysis 2005, 17, 1341.

[2] O. Rohr, Indust. Lubric. Tribol. 2002, 54, 153.

[3] J. Wang, J. Lu, S. B. Hocevar, P. A.M. Farias, B. Ogorevc, Anal. Chem. 2000, 72, 3218.

[4] A. Economou, Trends Anal. Chem. 2004, 24, 334.

[5] J. Wang, J. Lu, Electrochem. Commun. 2000, 2, 390.

[6] J. Wang, R. P. Deo, S. Thongngamdee, B. Ogorevc, Electroanalysis 2001, 13, 1153.

[7] J. Wang, J. Lu, Ü. A. Kirgös, S. B. Hocevar, B. Ogorevc, Anal. Chim. Acta 2001, 434, 29.

[8] J. Wang, Ü. A. Kirgös, J. Lu, Electrochem. Commun. 2001, 3 , 703.

[9] E. A. Hutton, B. Ogorevc, S. B. Hocevar, F. Weldon, M. R. Smyth, J. Wang, Electrochem. Commun. 2001, 3, 707.

[10] S. B. Hocevar, J. Wang, R. P. Deo, B. Ogorevc, Electroanalysis 2002, 14, 112.

[11] S. B. Hocevar, B. Ogorevc, J. Wang, B. Pihlar, Electroanalysis 2002, 14, 1707.

[12] E. A. Hutton, S. B. Hocevar, B. Ogorevc, M. R. Smyth, Electrochem. Commun. 2003, 5, 765.

[13] G. Kefala, A. Economou, A. Voulgaropoulos, M. Sofoniou, Talanta 2003, 61, 603.

[14] A. Krolicka, A. Bobrowski, K. Kalcher, J. Mocak, I. Švancara, K. Vytras, Electroanalysis 2003, 15, 1859.

[15] C. E. Banks, J. Kruusma, M. E. Hyde, A. Salimi, R. G. Compton, Anal. Bioanal. Chem. 2004, 379, 277.
[16] A. Krolicka, A. Bobrowski, Electrochem. Commun. 2004, 6, 99.

[17] M. Yang, Z. Hu, J. Electroanal. Chem. 2005, 583, 46.

[18] J. Wang, J. Lu, S. B. Hocevar, B. Ogorevc, Electroanalysis 2001, 13, 13.

[19] R. O. Kadara, I. E. Tothill, Anal. Bioanal. Chem. 2004, 378, 770.

[20] K. Vytřas, I. Švancara, R. Metelka, Electroanalysis 2002, 14, 1359.

[21] A. Królicka, R. Pauliukaite, I. Švancara, R. Metelka, A. Bobrowski, E. Norkus, K. Kalcher, K. Vytřas, Electrochem. Commun. 2002, 4, 193.

[22] R. Pauliukaite, R. Metelka, I. Švancara, A. Królicka, A. Bobrowski, K. Vytřas, E. Norkus, K. Kalcher, Anal. Bioanal. Chem. 2002, 374, 1155.

[23] G. U. Flechsig, M. Kienbaum, P. Gründler. Electrochem. Commun. 2005, 7, 1091.

[24] G. U. Flechsig, O. Korbout, S. B. Hocevar, S. Thongngamdee, B. Ogorevc, P. Gründler, J. Wang, Electroanalysis 2002, 14, 192.

[25] C. E. Banks, J. Kruusma, R. R. Moore, P. Tomćik, J. Peters, J. Davis, Š. Komorsky-Lovric, R. G. Compton, Talanta 2005, 65, 423.

[26] R. Pauliukaite, S. B. Hocevar, B. Ogorevc, J. Wang, Electroanalysis 2004, 16, 719.

[27] R. Pauliukaite, C. M. A. Brett, Electroanalysis 2005, 17, 1354.

[28] C. Gouveia-Caridade, C. M. A. Brett, Electroanalysis 2005, $17,549$.

[29] A. Economou, P. R. Fielden, Analyst 2003, 128, 205.

[30] G. Kefala, A. Economou, A. Voulgaropoulos, Analyst 2004, 129, 1082.

[31] C. Gouveia-Caridade, C. M. A. Brett, in press.

[32] C. M. A. Brett, L. Angnes, H.-D. Liess, Electroanalysis 2001, $13,765$.

[33] O. M. S. Filipe, C. M. A. Brett, Electroanalysis 2004, 16, 994.

[34] C. M. A. Brett, D. A. Fungaro, J. Braz. Chem. Soc. 2000, 11, 298.

[35] M. E. R. Dam, K. N. Thomsen, P. G. Pickup, K. H. Schrøder, Electroanalysis 1995, 7, 70. 